\title{
Simulated Acoustic Field in Mudejar-Gothic Churches
}

\author{
M. Galindo ${ }^{\dagger}$, T. Zamarreño ${ }^{\dagger}$, S. Girón ${ }^{\dagger}$, J. J. Sendra ${ }^{*}$, and J. Navarro ${ }^{*}$ \\ ${ }^{\dagger}$ Department of Applied Physics, ${ }^{*}$ Department of Architectural Constructions. \\ Seville University. Avda Reina Mercedes, 2; 41012-Sevilla (Spain)
}

Summary: In this work we have undertaken an acoustic simulation of the sound field in several churches in the city of Seville. The simulation has been carried out through the RAYNOISE program and has been based on the reverberation times measured in those spaces. We have focused on Sound Pressure Levels SPL, Clarity C80 and Definition D50 indices data in relation to their spectral variations and spatial distributions and their comparison with the experimental values.

\section{INTRODUCTION}

Mudejar style is a link between Islamic art and western Christian art, so it is a uniquely Spanish artistic movement. These churches were probably built between the thirteenth and fifteenth centuries and they were built of brick. All the churches analysed have similar architectural features: three naves covered with wooden frameworks following in the Moorish style and a vaulted presbytery. Sendra et al (1-3) have pointed out that the smaller size of these churches and mainly their wooden ceilings significantly improve their acoustical behaviour, as far as this can be indicated by reverberation times, over the Gothic contemporaries. The greater absorption in the ceilings tends to lead to a decrease of the great reverberation times expected in these large volumes, above all at low frequencies.

Besides being used for worship which implies the use of speech and music, these buildings are sometimes renovated and used as lecture halls, theatres, or auditoria. According to the specialist Angulo (4), this type of church is called "the Seville parish type".

\section{OBJECTIVES}

Our main aim in this work is to show the agreement between the experimental data and the simulated results performed by the ray tracing method (RAYNOISE version 2.1a) in this type of architectural enclosures. We are specially interested in researching the ability of the software to predict the spectral variations and spatial distribution of the measured acoustic parameters. We mainly focus on the SPL and on the acoustic indices C80 and D50. The measurement tests as well as the simulations have been carried out inside the unoccupied churches.

\section{GENERAL ASPECTS}

Using an iterative procedure we have adjusted the absorption coefficients of the different wooden ceilings, which are the most singular ones, until we obtained the simulated reverberation 
times in a range of $\pm 10 \%$ of the in situ experimental results (see table 1). Those absorption coefficient values are contrasted with other similar data in the bibliography.

The geometrical and acoustical model is built in this way and the whole simulation process is executed with maximum order of reflection $\mathrm{R}$ equal to 10 . The number of rays $\mathrm{N}$ is determined by the specifications of the program user's manual by the formula $1256,6 \mathrm{I}^{2} \mathrm{~N}^{-1}<\mathrm{S}_{\mathrm{c}}$, with 1 the mean free path $(\mathrm{m})$ and $\mathrm{S}_{\mathrm{c}}$ the characteristic surface $\left(\mathrm{m}^{2}\right)$ of the geometric model. To decide when to abandon a ray, in addition to the order of reflection, we use a dynamic rang of $60 \mathrm{~dB}$ and a time window, following the manufacturer's suggestion, $\mathrm{t}_{\mathrm{w}}=0,0294 \mathrm{l}(\mathrm{s})$.

Calculations have been carried out using the Conical Beam Method (CBM) and we have considered the air absorption and the sound velocity at the atmospheric conditions of $20^{\circ} \mathrm{C}$ and $50 \%$ relative humidity, similar to that at the measurement time.

The background noise in each simulation process coincides with the measured noise spectra. Likewise we have made calculus modifying the diffusion conditions of the ceilings and audience zone. This does not have a marked effect on any evaluated parameters in the same way as Lam (5) has already pointed out.

An omnidirectional source with the known sound power spectrum of the real one has been used to obtain simulated sound pressure levels. Both calculation options, image and mapping, have been set to obtain the acoustic parameters implemented and to compare with the experimental data.

Receiver surfaces and microphones have been placed at $1,20 \mathrm{~m}$ above floor level.

TABLE 1: Measured reverberation times $T_{\text {meas }}$ and simulated $T_{\text {sim }}$

\begin{tabular}{lllllll}
\hline & \multicolumn{2}{c}{ Santa Marina } & \multicolumn{2}{c}{ San Vicente } & \multicolumn{2}{c}{ Santa Catalina } \\
Freq. (Hz) & $\mathrm{T}_{\text {meas }}$ & $\mathrm{T}_{\text {sim }}$ & $\mathrm{T}_{\text {meas }}$ & $\mathrm{T}_{\text {sim }}$ & $\mathrm{T}_{\text {meas }}$ & $\mathrm{T}_{\text {sim }}$ \\
\hline 250 & 3,62 & 3,71 & 1,71 & 1,70 & 1,50 & 1,48 \\
500 & 3,96 & 4,11 & 1,81 & 1,79 & 1,72 & 1,64 \\
1000 & 4,00 & 4,01 & 1,82 & 1,78 & 1,75 & 1,68 \\
2000 & 3,57 & 3,70 & 1,68 & 1,70 & 1,67 & 1,57 \\
4000 & 2,62 & 2,68 & 1,40 & 1,45 & 1,45 & 1,36 \\
\hline
\end{tabular}

\section{RESULTS AND CONCLUSIONS}

Figure 1 shows a view of the 3D model created for San Vicente church. Figure 2 shows the measured and computer calculated values of the sound pressure levels (relative to that produced by the sound source in a free field at $10 \mathrm{~m}$ ) versus source-receiver distance at 500 , and $2000 \mathrm{~Hz}$ octave

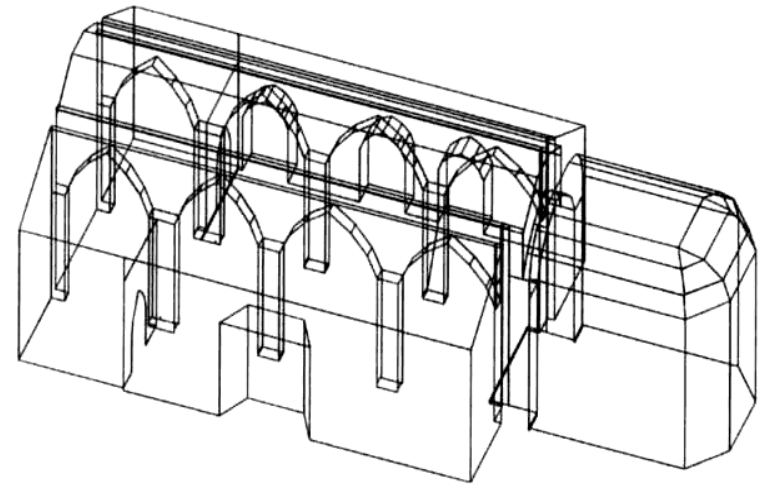

FIGURE 1. 3D model used for simulations in San Vicente Church. 

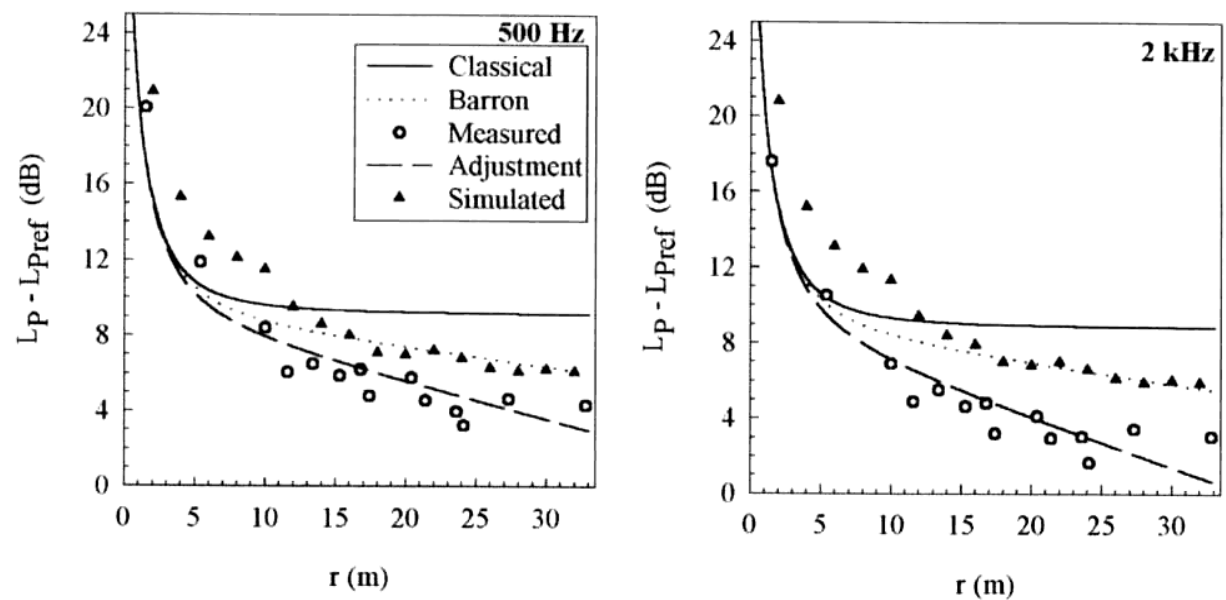

FIGURE 2. Lp-Lpref (dB) versus distance r (m) at 500 and $2000 \mathrm{~Hz}$ octave bands for San Vicente church.
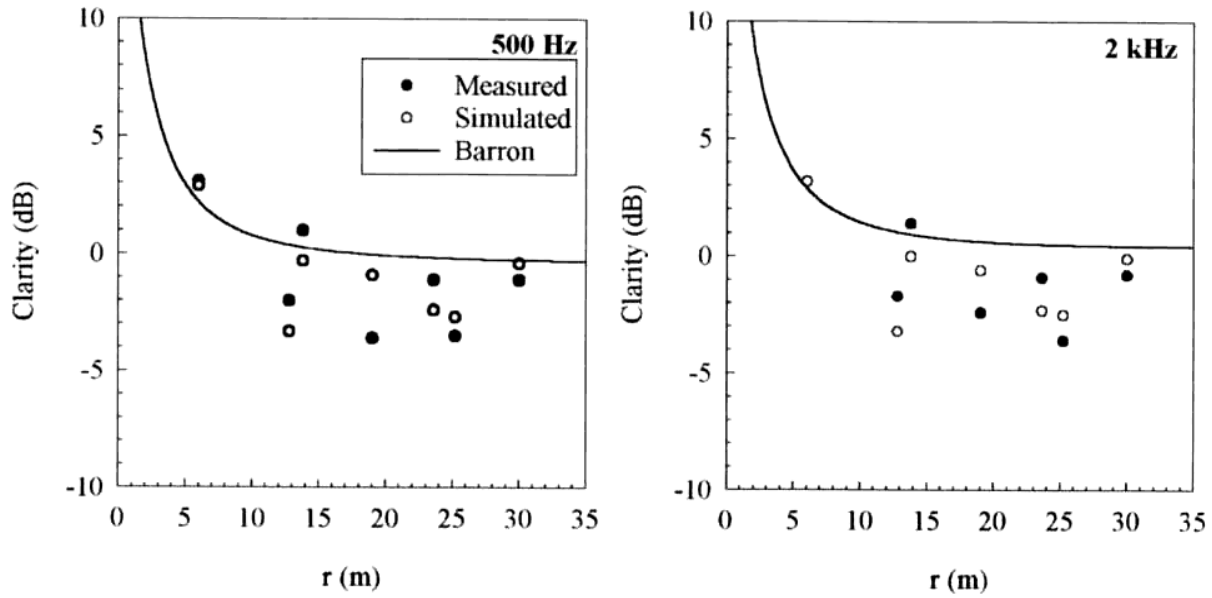

FIGURE 3. C80 (dB) versus distance $r(\mathrm{~m})$ at 500 and $2000 \mathrm{~Hz}$ octave bands for San Vicente church.

bands in this church. The same graphics show the theoretical curves obtained through classical diffuse field model, Barron's modified model (6) and an adjusted curve of the experimental results.

As we can see the simulated levels continue to decrease further we go beyond the critical distance according to Barron's model, but the measured values differ appreciably from expected theoretical levels although the same tendency suggested by Barron's modified model for attenuation by distance is observed.

Similarly figures 3 and 4 compare the measured and simulated values of C80 and D50 respectively as a function of distance at the same octave bands. In both cases we superimposed (continuous line) the values from Barron's model. Both sets of values show similar spectral and spatial patterns, and they show these two acoustic quality descriptors are rather sensitive to local variations, there being no agreement with the predicted theoretical model.

Quite a satisfactory agreement between measured and simulated results has been achieved by RAYNOISE computer simulation, mainly for the early to late energy indices in these complex rooms. In this respect it is useful to remember the uncertainties that arise from the reproducibility of measurements and absolute positions of microphones in a real church and its model description (7). 

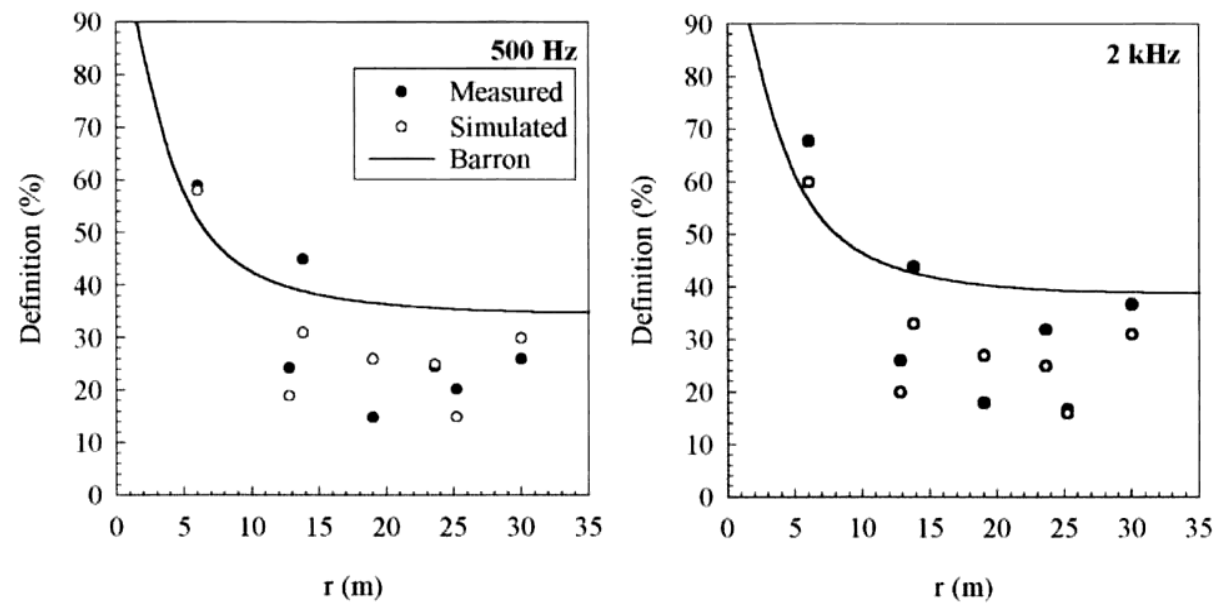

FIGURE 4. D50 (\%) as a function of distance $\mathrm{r}(\mathrm{m})$ at 500 and $2000 \mathrm{~Hz}$ octave bands for San Vicente church.

We have optimised the simulation procedure taking into account the measured reverberation times, so the simulation process can be used in this way to improve any remodeling process from an acoustic point of view.

In the future we are interested in contrasting these facts with other acoustic indices such as STI/RASTI and LEF, also using other software tools.

\section{REFERENCES}

1. Sendra, J. J., Zamarreño, T., "El campo sonoro en las iglesias Gótico-Mudéjares con cubierta de madera: Aplicación del modelo de Barron," in Proceedings of Tecni-Acústica'95, XXVI Jornadas Nacionales de Acústica, La Coruña, Spain, pp. 87-90, 1995.

2. Sendra, J. J, Zamarreño, T., Navarro, J., "An analytical model for evaluating the sound field in Gothic-Mudejar churches," in Proceedings of Second International conference on Computational Acoustics and its Environmental Applications Compac 97, Terni, Italy, pp.139-148, 1997.

3. Zamarreño, T., Galindo, M., Girón, S., "Predicción de índices acústicos en iglesias GóticoMudéjares," in Proceeding of XXVI Reunión Bienal de la Real Sociedad Española de Física y Química, Las Palmas de Gran Canaria, Spain, pp.25-26, 1997.

4. Angulo, D., "Arquitectura mudéjar sevillana de los siglos XIII, XVI y XV," Ayuntamiento de Sevilla, Sevilla, pp. 32, 1983.

5. Lam, Y. W., Journal of the Acoustical Society of America 100, pp. 2181-2203 (1996).

6. Barron, M., Lee, L. J., Journal of the Acoustical Society of America 84, pp. 618-628 (1988).

7. Pelorson, X., Vian, J. P., Polack, J. D., Applied Acoustics 37, pp. 175-198 (1992). 